\title{
Inside Out: Dialogical Design of Digital Drama
}

\author{
Mika 'Lumi' Tuomola \\ Crucible Studio at Media Lab Helsinki, The Department of Media, Aalto University School of Art and Design \\ Hämeentie 135 C, 00560 Helsinki, Finland \\ mika.tuomola@aalto.fi
}

\begin{abstract}
This paper introduces a common thread for a talk about four experimental digital drama productions. The introduction is followed by the short descriptions of the productions: Daisy's Amazing Discoveries (1996), Shift (2002), Accidental Lovers (2006) and Alan01 (2010).
\end{abstract}

Drama, Narrative, Storytelling, Design, Digital, Interactive, Generative, Procedural, Participatory

\section{INTRODUCTION}

This paper is a short description of four experimental digital drama productions that I will discuss in the Create10 interaction design conference keynote presentation June 30, 2010 at Edinburgh Napier University, UK. The productions, in all of which l've been in lead artistic positions, have been created between 1995-2010 in various contexts from production companies to universities, while their media platforms vary from Internet and installation to television and mobile devices. In my talk, however, I hope that the investigation of the fifteen-year period from various crucial design points of view to digital drama will offer a common thread and provide insights for the future development:

1. Inside out: how to bring both designers'/authors' and users'/participants' internal intentions into a dramatically interesting dialogue/chorus within a mediated interaction environment?

2. Dialogue and media design: what kinds of media database, system, interaction and narrative logics may be able to generate a dramatic interactive experience with coherent audiovisual language?

3. Digital drama: how have the audience genre expectations evolved (e.g. via games and social media) considering what a digital drama experience is and how does it influence our design work?

\section{DAISY'S AMAZING DISCOVERIES}

The production of Daisy's Amazing Discoveries (Tuomola 1996) by Coronet Interactive Ltd in coproduction with Media Lab Helsinki, University of Art and Design (now Aalto University School of Art and Design), Finland, started in 1995, and the learning experiences were written into a two-part Digital Creativity Journal article (Tuomola \& Leskinen 1998). Currently, the most elaborate description and contextualisation available may be the one by Steve Dixon (Dixon 2007):

"In historical terms 1996 was the key year, with the emergence of three different photoplay soap operas. These included sixteen episodes of a gay soap Fatal Beauty, and The Spot, reputedly the first soap on the web, which began early in 1996 and ran for almost two years... Daisy's Amazing Discoveries, a five-part nonlinear interactive drama, also came online in 1996, and was in its day by far the most theatrical and artistically sophisticated example of the genre. The ambitious, state-of-theart Finnish production (in English) traces Daisy's journey as she leaves a travelling circus to pursue her romantic dreams in the city. It is innovative in both concept and design, with imaginative interactive elements, and some stunning and elaborate photomontage interface screens created in Photoshop."

"The rich and surreal screen environments enable a range of routes through the narratives; for example, clicking on different paving stones on a road winding into the distance reveals twelve separate scenes. In addition to the photomontage environments, the production incorporates textand-image collages, audio dialogue accompanied by photographic slideshows, music, and a small number of video clips. As each episode was released on the web, users could move up a level of interactivity to become participatory. They could affect the action in the next episode by writing to the fictional world's lifestyle magazine, by scrawling graffiti messages in the restroom of the bar, or by entering the environments chat room." (Dixon 2007) 


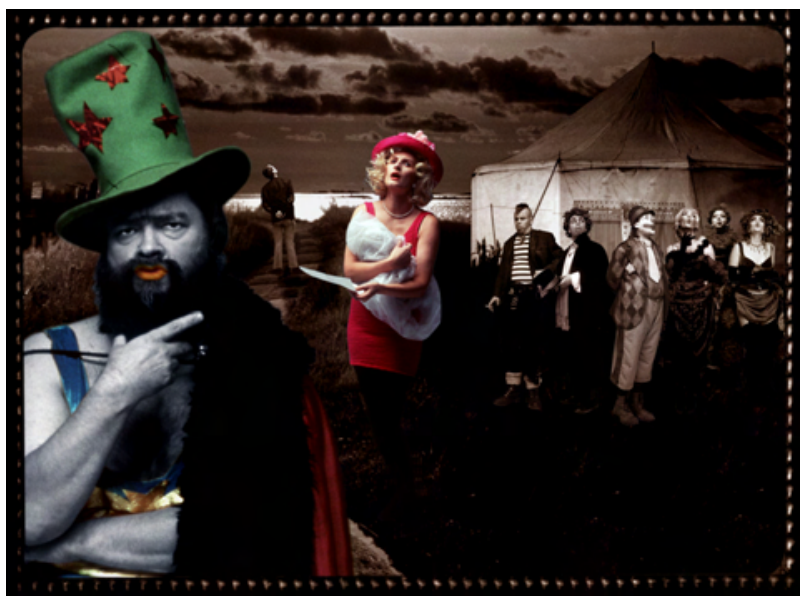

Figure 1: Daisy's Amazing Discoveries (image by Marja Vainionpää, photographs by Kari Kankainen).

\section{SHIFT}

"People say that what we're all seeking is a meaning of life. I don't think that's what we're really seeking. I think that what we're seeking is an experience of being alive, so that our life experiences on the purely physical plane will have resonances within our own innermost being and reality, so that we actually feel the rapture of being alive." (Campbell 1991)

Shift (Tuomola 2002) was produced as an experimental production outcome of the Helsinki Media Lab Fall 2001 seminar Myth and Digital Media (Randlepp 2002). The seminar investigated comparative mythologist Joseph Campbell's approach to myths of various cultures, while the approach was reflected upon in terms of contemporary culture by investigating the possibilities of influencing or contributing to the arising cultural narratives, patterns and images, the systems of representation in digital media. Shift was realised to simulate the nonlinear seminar discussion and give flesh to it through the means of moving image, dance and music.

Twelve hours of seminar discussion about the significance of myths in today's world were recorded on video, analysed and sorted out into 316 statements and questions. The points of view in the preceding material were dramatised into highly associative, poetic or aphoristic lines for two dramatis personae: materialist-atheist-pragmatist Woman/Ying and idealist-mystic-dreamer Man/Yang. The lines were voice recorded and experimented further with so that the computer could play them in any random order, yet still the illusion of dialogue would be maintained.

We shot, edited and added twenty-six contemporary, associative dance clips of Buddha dancing (choreographed and danced by Aki Suzuki). The dance clips were produced in a manner suggesting that Woman and Man are talking inside Buddha's stomach. Also, generative film music of various moods was produced.

In the final outcome of Shift, the voice-overs, video and music are edited real-time 24/7 by computer using both randomisation and a very simple likelihood logic of media organisation. The number of possible works created is, as they say, infinite, while the public gallery exhibits (e.g. Arctic Art 2002, Tromsø, Norway) showed that the 24/7 generative computer-edit seems completely human edited. Shift demonstrates the possibilities of algorithmically directed databases, associative and metaphorical script writing - and chance - as opportunities for creating more complex computergenerated characters and for making the generally mechanical behaviour of computers more invisible and unexpected.

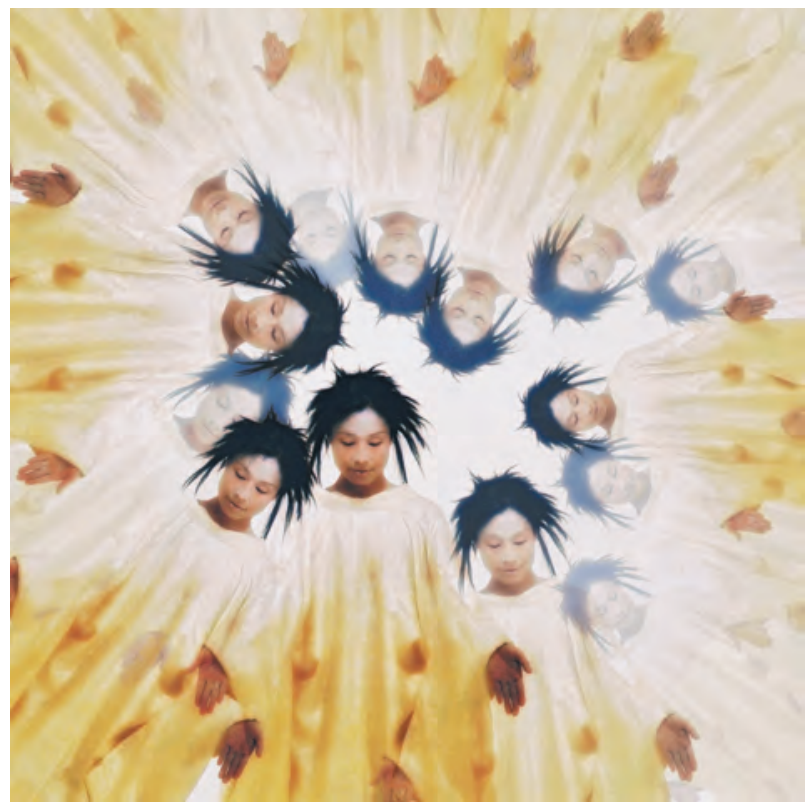

Figure 2: Shift (image by Egon Randlepp, photograph by Juhani Tenhunen).

\section{ACCIDENTAL LOVERS}

"Don't believe him, he'll break your heart!" "Go ahead! Let yourselves go. Love conquers everything!" "To have any chance for long-term happiness in a personal relationship, you need to be honest, you cannot hide anything." Have you ever shouted or thought out advice for fictional characters? Have you ever wanted to express your interpretation of a story theme to others? Have you ever wanted to influence the plot of a television series?

The interactive dark musical comedy series Accidental Lovers (Tuomola 2006, Korpilahti 2010) 
enabled this to the Finnish television audiences each Wednesday and Friday evening between 27 December 2006 and 5 January 2007. It featured as main characters the sixty-one-years old cabaret singer Juulia (Kristiina Elstelä) and thirty-yearsyounger pop star Roope (Lorenz Backman), who met as next-door neighbors in Merihaka, Helsinki.

Viewers were able to influence the unfolding drama whist it was being presented, by sending mobile text messages to the broadcast encouraging, or attempting to spoil, a possible love affair between the two unlikely lovers. The messages were completely unstructured: viewers could send any thoughts, any suggestions, any directions, at any point during each episode.

A glowing heart showed whether the audience messages were warming or cooling the hearts of the romantic couple, and viewers saw the relationship develop according to their comments to and discussion with characters and other audience members (see Figure 3). To enhance the sense of participation, while all viewers received a personal text message from the broadcast system, some viewers saw their selected text messages displayed on the screen and heard the characters voice-over response to their texts. Accidental Lovers is thus a conversation between participating viewers and the dramatic production, but also, as an inherent effect, between the participants themselves. Many "cycles of love" were broadcasted in a row, creating a cyclical dramaturgical structure comparable to films like Lola rentt (Tykwer 1998) and Groundhog Day (Ramis 1993).

Each episode was automatically edited in real time to best reflect the input received from the participating viewers. Both the authoring of the computational narrative structures, on whose basis the automatic editing was carried out, and the realtime automatic reasoning and delivery, were done with the nm2 (Stollenmeyer 2007) ShapeShifting Media Technology tools (Ursu 2008). The software continuously analysed viewers' text messages and automatically directed the choice of events, the mood, and the pace of the narrative, by choosing how the video and audio clips and graphics objects should be assembled. These were conveyed as playlists to the playout system, which used PubliTronic Indigo hardware for real-time rendering. The text messages selected for inclusion in the narration had to be, and were, moderated by a human operator, using a Text Message Moderation tool built as an add-on to the ShapeShifting Media System.

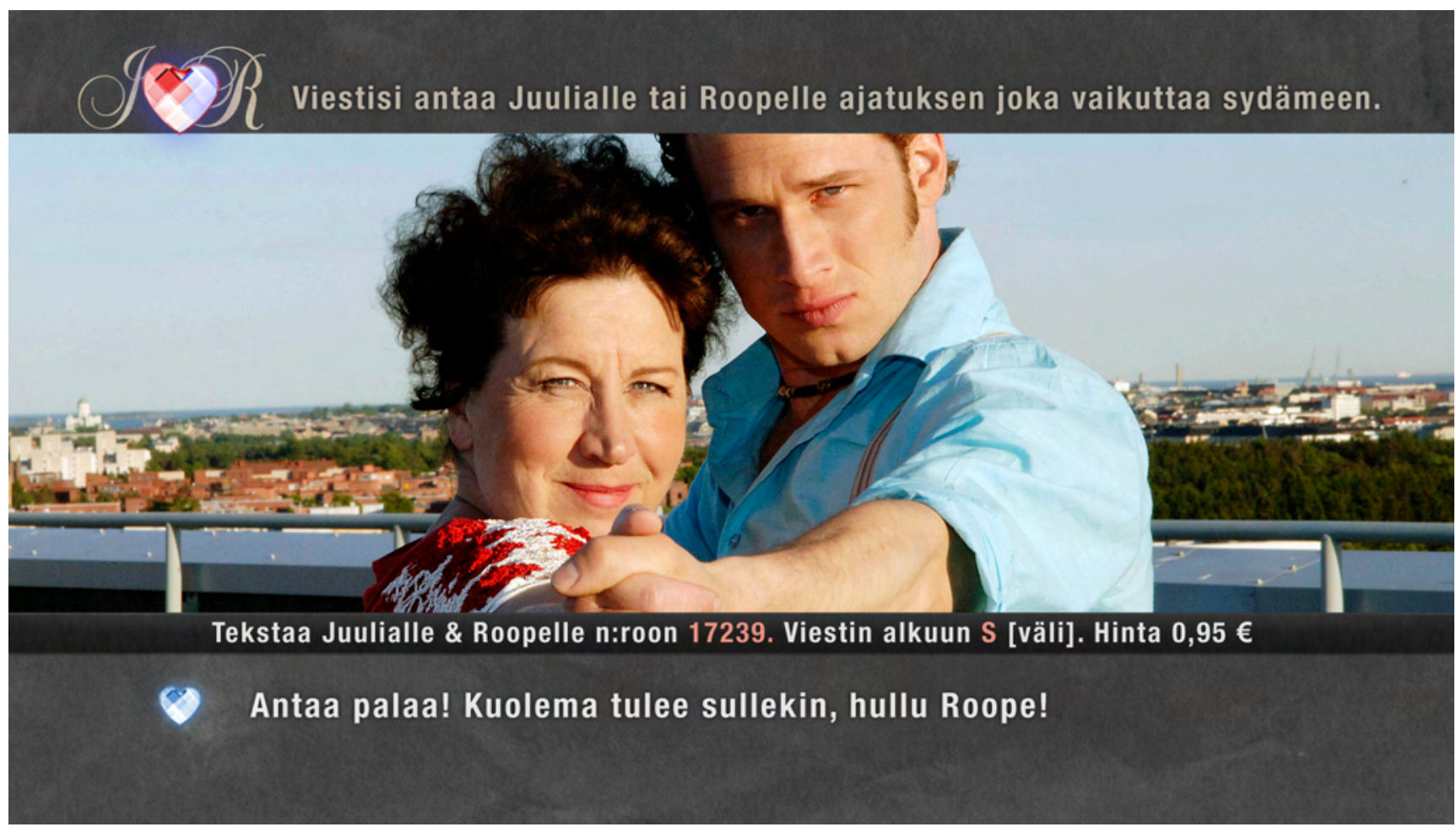

Figure 3: Accidental Lovers television screen (photo by Heli Sorjonen, graphics by Pontus Vepsäläinen). Translation of interface text: on top bar, authored: "Your message gives a thought for Juulia or Roope and affects the big heart." On middle bar, authored: "Text to Juulia \& Roope to number 17239. Start message with S [space]. Price 0,95 €." On bottom bar, text message from a TV viewer: "Go for it! You will die too, crazy Roope!" 
Accidental Lovers is constructed as a superimposition of voiceovers on video clips, with very little lip-sync material. In order to produce constantly reusable moving images within the story structure, the original storyboards and shooting plan were based on very theatre-like blocking of characters for the camera, together with location clarifying large shots, emotion carrying close-ups and associative, symbolic images in between. The working premise was that the character's point of view in each situation would be carried by voiceovers (Juulia's or Roope's thoughts within each scene).

Cumulatively, during the overall 12 broadcasts, Accidental Lovers attained over a million television viewers, while each episode audience number varied between 40-100 thousand viewers, with the peak audience groups being $20+$ men and 60+ women. This fulfilled the goal of breaking the generation and genre gaps. The participating viewers sent almost three thousand text messages to the show: advice to the characters, opinions about them, comments about love and even their own alternate fantasy scenes.

\section{ALAN01}

The Alan01 interactive installation (Pesonen 2010, Korpilahti 2010) investigates associational storytelling and interaction structures, highlighting the patterns of human-machine communication. The work's primary themes are derived from Alan Turing's (1912-1954) life, particularly his ideas of machine-based consciousness and prosecution for having been homosexual. By choosing these subjects as the main themes of the installation, we have wanted to acknowledge all the people past, present and coming, who were, are and will be treated unjustly in our societies, while Turing's own ideas of computable consciousness serve as a model for interaction design as an artistic expression.

Alan01 is exhibited at the MoA Festival, the Elefantti quarters of the Helsinki city centre, Finland, 12th May-13th June 2010. It is also to be exhibited in the ACM Multimedia 2010 Interactive Art Program at the Palazzo Medici-Riccardi, Florence, Italy, October-November 2010.

\section{REFERENCES}

Campbell, J. (1991) The Power of Myth. Doubleday, New York.

Dixon, S. (2007) Digital Performance - A History of New Media in Theater, Dance, Performance Art, and Installation. MIT Press, Cambridge Massachusetts.

Korpilahti, T. etc. (2010) Accidental Lovers Crucible Studio site. http://crucible.mlog.taik.fi/productions/ accidental-lovers/ (June 5, 2010)

Korpilahti, T. \& Stolt, T. etc. (2010) Alan01 Crucible Studio site. http://crucible.mlog.taik.fi/productions/ alan01/ (June 5, 2010)

Pesonen, J (dir.), Korpilahti, T., Nieminen, M., Saarinen, L. Tuomola, M. etc. (2010) Alan01. Interactive installation. Crucible Studio at Media Lab Helsinki, Aalto University School of Art and Design.

Ramis, H. (dir.) (1993). Groundhog Day. Movie. Columbia Pictures Corporation, USA.

Randlepp, E. etc. (2002) Myth and Digital Media. http://mlab.taik.fi/myth/ (June 7, 2010).

Stollenmeyer, P. etc. (2007) nm2 - new millennium, new media EU FP6 project web site. http://www.istnm2.org/ (June 5, 2010)

Tuomola, M. (dir.), Vainionpää, M., Kivelä, A. etc. (1996) Daisy's Amazing Discoveries. http://daisy.uiah.fi/ (June 7, 2010).

Tuomola, M. (dir.) etc. (2002) Shift. Generative dance movie production (available on CD). Media Lab Helsinki, Aalto University School of Art and Design.

Tuomola, M. (dir.), Saarinen, L., Nurminen, M. etc. (2006) Accidental Lovers (Sydän kierroksella). Interactive dark musical comedy for television. Crucible Studio at Media Lab Helsinki, Aalto University School of Art and Design \& YLE, The Finnish Broadcasting Company. Broadcast on Channel TV1 by YLE, December 2006 - January 2007.

Tuomola, M. \& Leskinen, H. (1998). Daisy's Amazing Discoveries: Part I - The Production \& Part II - Learning from Interactive Drama. Digital Creativity Journal. Vol. 9, No. 2-3, pp. 75-90 \& 137152.

Tykwer, T. (dir.) (1998) Lola rennt. 1998. Movie. XFilme Creative Pool, Germany.

Ursu, M., Thomas, M., Kegel, I., Williams, D., Tuomola, M., Lindstedt, I., Wright, T., Leurdijk, A., Zsombori, V., Sussner, J., Myrestam, U. \& Hall, N. (2008) Interactive TV Narratives: Opportunities, Progress and Challenges. ACM Transactions on Multimedia Computing, Communications, and Applications. Vol. 4, Issue 4, Article No. 5. 